\title{
Outcome of surgical treatment of adenocarcinoma in Barrett's oesophagus
}

\author{
M B E Menke-Pluymers, N W Schoute, A H Mulder, W C J Hop, M van Blankenstein, \\ $\mathrm{H}$ W Tilanus
}

\begin{abstract}
A retrospective study was performed of an 11 year period (1978-88) to analyse the survival of 112 patients ( 85 men and 27 women, mean age 63 years) with adenocarcinoma in a columnar lined (Barrett's) oesophagus in respect of surgical treatment, tumour staging, and histological grading. Presenting symptoms were dysphagia $(60 \%)$ and pain $(25 \%)$. Only six patients were previously known to have a columnar lined oesophagus. Eighty five patients $(76 \%)$ underwent partial resection of the oesophagus and cardia. Postoperative mortality was $6 \%$. After resection $(n=85)$, the 5 year survival was $24 \%$. Survival was significantly better for patients without regional lymph node metastases (stage 0 , I, IIA $(n=61)$ : 5 year survival $30 \%$ ) and even better if the tumour was restricted to the submucosa (stage $0, I(n=12)$ : 5 year survival $63 \%$ ). Survival was not influenced by the histological grade of the tumour. Staging based on infiltration of the oesophageal wall and lymph node spread is valuable in determining the prognosis for patients with adenocarcinoma in Barrett's oesophagus.

(Gut 1992; 33: 1454-1458)
\end{abstract}

Barrett's oesophagus ${ }^{12}$ represents a metaplastic transformation of the normal squamous cell epithelium of the lower tubular oesophagus into columnar epithelium. ${ }^{3}$ The premalignant character of Barrett's oesophagus is shown by a progession from benign columnar epithelium into dysplasia and adenocarcinoma. ${ }^{45}$ Although endoscopic surveillance and biopsy are performed to achieve an early diagnosis of malignant degeneration, many patients with Barrett's oesophagus present primarily with symptoms of an oesophageal carcinoma.

The survival of patients with an adenocarcinoma in Barrett's oesophagus is low, even after oesophagectomy. ${ }^{67}$ The influence of infiltration of the oesophageal wall, lymph node metastases, and the histological grade of the tumour on the prognosis is not fully understood. This retrospective study aimed to analyse the survival of patients with an adenocarcinoma in columnar lined oesophagus in relation to surgical treatment, staging, and the differentiation grade of the tumour.

\section{Patients and methods}

During the period 1978-88, 112 consecutive patients with an adenocarcinoma in a columnar lined lower oesophagus were referred to the Rotterdam Oesophageal Tumour Study Group for evaluation and treatment. The patient popu- lation consisted of 85 men (76\%) and 27 women $(24 \%)$, with a mean age of 63 years (range 30-96 years).

Barrett's columnar lined oesophagus is defined as the condition in which columnar type epithelium is found at least $3 \mathrm{~cm}$ above the distal end of the oesophagus as endoscopically defined. The demarkation between stomach and oesophagus is endoscopically determined by the change in diameter of the lumen, colour of the mucosa, and vascular pattern. The upper level was diagnosed by the columnar-squamous epithelial border, which was always easily identified. For the purpose of this investigation, we studied those patients with a biopsy proven adenocarcinoma of the distal tubular oesophagus, in whom columnar epithelium of the oesophagus above the carcinoma was visible macroscopically at endoscopy, meeting the above definition of Barrett's oesophagus. Patients with a carcinoma of the cardia were excluded.

A careful medical history, covering the total lifespan, in respect of symptoms of reflux and antireflux treatment was obtained. Before operation all patients underwent general physical examination and electrocardiographic and lung function studies to determine their general fitness for operation. Chest $x$ ray, barium swallow studies, endoscopy with biopsy, ultrasound examination of the liver and upper abdominal areas, and in cases of high or mid-oesophageal tumours, bronchoscopy, were performed. Since 1980 , computer tomography of the thorax and upper abdomen and ultrasound examination of the neck have been carried out in order to identify abnormal lymph nodes, which are then subjected to cytological examination. ${ }^{8}$ All patients considered inoperable on the grounds of general health or with distant metastases or extension of the tumour into the bronchus were not considered for resection.

During the period 1978-85 all patients who were considered for resection $(n=72)$ received preoperative radiation therapy (40 Grays over four weeks). In two randomised prospective studies, however, no advantage of preoperative radiation therapy could be shown..$^{90}$ Therefore, from 1986-8 preoperative radiation therapy was no longer given $(n=27)$. Hospital mortality was defined as the mortality during the postoperative stay in hospital.

Based on pathological analysis of the resection specimens, postoperative staging was performed according to the pTNM classification of the UICC (International Union Against Cancer) $1987^{\prime \prime}$ (Table I). At least half of the tumour was examined histologically. Areas in which deep invasive growth was suspected were selected. 
TABLE I $P$-TNM classification of oesophageal carcinoma according to the International Union Against Cancer (UICC 1987 in the study group

\begin{tabular}{|c|c|c|c|c|}
\hline \multirow{5}{*}{$\begin{array}{l}\text { Stage } \\
\text { Stage 0: } \\
\text { Stage I: } \\
\text { Stage IIA: }\end{array}$} & \multicolumn{2}{|c|}{ Regional metastases } & \multirow{2}{*}{$\begin{array}{l}\begin{array}{l}\text { Distant } \\
\text { metastases }\end{array} \\
\text { M0 }\end{array}$} & \multirow{2}{*}{$\frac{N o}{2}$} \\
\hline & Tis & No & & \\
\hline & $\mathrm{T} 1$ & No & M0 & 10 \\
\hline & $\mathrm{T} 2$ & No & M0 & 19 \\
\hline & $\mathrm{T} 3$ & No & M0 & 30 \\
\hline \multirow[t]{2}{*}{ Stage IIB: } & T1 & Nl & Mo & 1 \\
\hline & $\mathrm{T} 2$ & Nl & M0 & 4 \\
\hline \multirow{2}{*}{ Stage III: } & T3 & N1 & M0 & 13 \\
\hline & $\mathrm{T} 4$ & anyN & M0 & 2 \\
\hline Stage IV: & any $\mathrm{T}$ & anyN & M1 & 4 \\
\hline
\end{tabular}

Tis (carcinoma in situ), Tl (tumour invades lamina propria or submucosa), T2 (tumour invades muscularis propria), T3 submucosa), T2 (tumour invades muscularis propria), T3 structures), N0 (no regional lymph node metastases), N1 (regiona lymph node metastases), M0 (no distant metastases), Ml (distant metastases).

Areas immediately above the tumour were also investigated for the presence of metaplastic epithelium. Biopsy and resection specimens were reviewed for the differentiation grade of the tumour.

The follow up period ranged from 1 month to 9 years with a mean of 21 months. Survival was assessed by computerised life table analysis according to Kaplan-Meier. ${ }^{12}$ For all patients, survival after diagnosis was calculated. For comparison of the survival of subgroups of patients, the Log rank test was used. Other methods used are indicated in the text. $\mathrm{p}<0.05$ (two sided) was considered the limit of statistical significance.

\section{Results}

\section{SYMPTOMS AND SOCIAL HABITS}

The most important presenting symptoms were dysphagia (60\%) and pain (25\%). The patients' characteristics with respect to symptoms of gastro-oesophageal reflux and treatment are listed in Table II. Twelve patients (11\%) had undergone an antireflux operation in the past, with an interval between antireflux surgery and diagnosis of an oesophageal carcinoma ranging from 2 months to 33 years (median 4.75 years, mean 10 years). In three patients, a Nissen fundoplication had been performed, in three a Billroth II partial gastric resection, in one a high selective vagotomy, and in five patients the procedure performed for hiatal hernia was not precisely documented. Daily alcohol consumption was reported by $67 \%$ of the patients, with more than 4 units a day taken by $4 \%$. Fifty one per cent of the patients were cigarette smokers

TABLE II Symptoms of gastro-oesophageal reflux and treatment in patients with adenocarcinoma in columnar lined oesophagus

\begin{tabular}{llll}
\hline & $\begin{array}{l}\text { Patients } \\
\text { no }(\%)\end{array}$ & $\begin{array}{l}\text { Antireflux } \\
\text { medication } \\
\text { (no) }\end{array}$ & $\begin{array}{l}\text { Antireflux } \\
\text { surgery } \\
(\text { no })\end{array}$ \\
\hline Nomptoms & $39(35)$ & & \\
Heartburn/regurgitation & $62(55)$ & 33 & 12 \\
$\quad$ 1 year & $10(9)$ & 4 & 2 \\
$\quad$ 1-5 years & $9(8)$ & 5 & 1 \\
$\quad$ 5 year & $32(28)$ & 19 & 6 \\
$\quad$ unknown duration & $11(10)$ & 5 & 3 \\
Not documented & $11(10)$ & & \\
\hline
\end{tabular}

ENDOSCOPIC FINDINGS

Of all 112 patients with an adenocarcinoma, only $6(5 \%)$ had a previous biopsy proved history of columnar lined oesophagus. The area of adenocarcinoma was circular in 41 patients $(36 \%)$, and comprised more than half the circumference of the oesophagus in $19(17 \%)$. On average, the tumour covered a length of $5 \mathrm{~cm}$ of the distal tubular oesophagus (range $1-12 \mathrm{~cm}$ ). In the group of patients with a resectable tumour $(\mathrm{n}=$ 85 ) the mean (SD) length of the tumour was 4 (2) $\mathrm{cm}$, and in the group with an unresectable tumour $(\mathrm{n}=27)$ it was $6(2) \mathrm{cm}$ (Mann-Whitney U test: $\mathrm{p}=0.003)$. The columnar lined segment comprised 3-19 $\mathrm{cm}$ (mean $6 \mathrm{~cm}$ ) of the oesophagus above the tumour. Endoscopy showed a hiatal hernia in $72 \%$ of the patients.

\section{TREATMENT}

After preoperative screening, 99 patients (88\%) with an adenocarcinoma in columnar lined oesophagus were considered for surgical treatment. In 14 patients, a tumour that was not resectable or metastases were found at laparotomy. Eighty five patients $(76 \%)$ underwent a subtotal resection of the oesophagus and cardia. Reconstruction was made by gastric tube $(n=79)$ or colonic interposition $(n=6)$, with an intrathoracic anastomosis at the level of the azygos vein or a cervical anastomosis.

Postoperative complications occurred in 29 patients (morbidity rate $34 \%$ ), of which the most important were postoperative bleeding $(n=6)$, recurrent laryngeal nerve paresis $(n=6)$, and anastomotic leakage $(n=8)$. Cardiovascular complications in three, respiratory complications in two, and postoperative bleeding in one patient lead to death in six patients during the postoperative period in hospital (hospital mortality 6\%). None of the 14 patients whose tumour was found to be unresectable at laparotomy died in hospital after operation. Over the first period of study (1978-83), hospital mortality was $9 \%$, while over the second period (1984-8) it had fallen to $4 \%$ (Fisher's exact test: $\mathrm{p}=0.4$ ).

Sixty six of the $85(78 \%)$ resected patients had received radiation therapy (40 Grays over four weeks) before operation as a routine preoperative treatment until 1986. The 27 inoperable or unresectable patients were given palliative nonsurgical treatment.

\section{PATHOLOGICAL FINDINGS AND STAGING}

Slides were reviewed to determine the differentiation grade of the tumour. In two cases the tumour was classified as well differentiated, in 52 as moderately differentiated, and in 58 cases as poorly differentiated.

In $95 \%$ of the cases, the margins of the resected specimens were free of tumour tissue on histological examination, but in four cases $(5 \%)$ microscopical remnants were found.

Patients were classified according to the pTNM classification as shown in Table I.

At the end of the study, 26 patients were alive, 


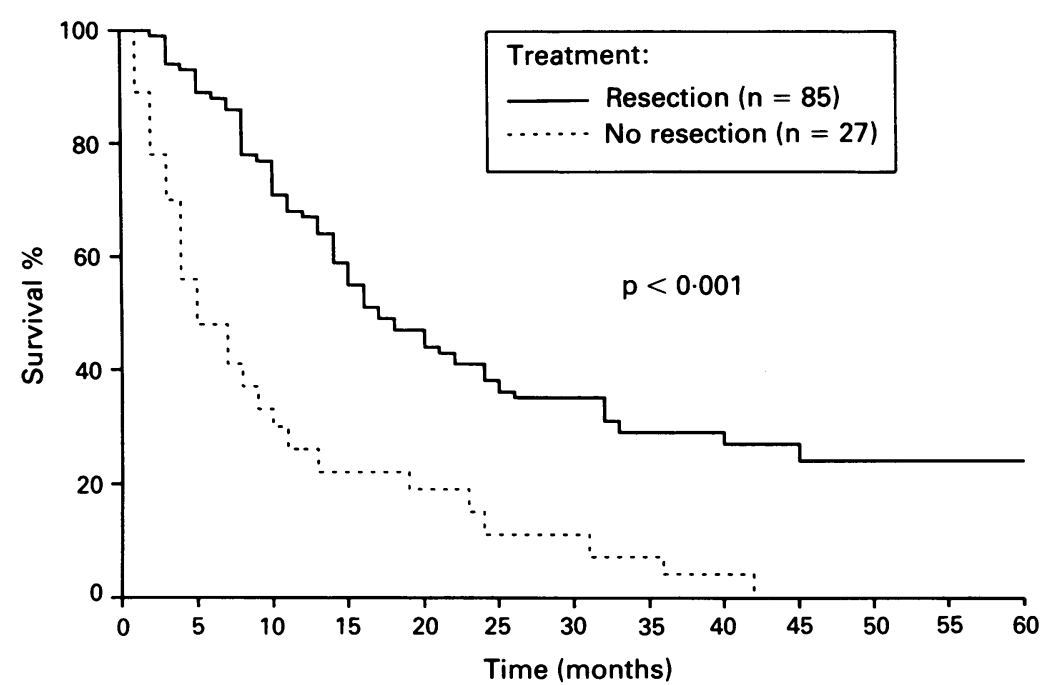

Figure 1: Survival (all causes) of patients treated by oesophagectomy $(n=85)$ versus inoperable or unresectable patients $(n=27)$.

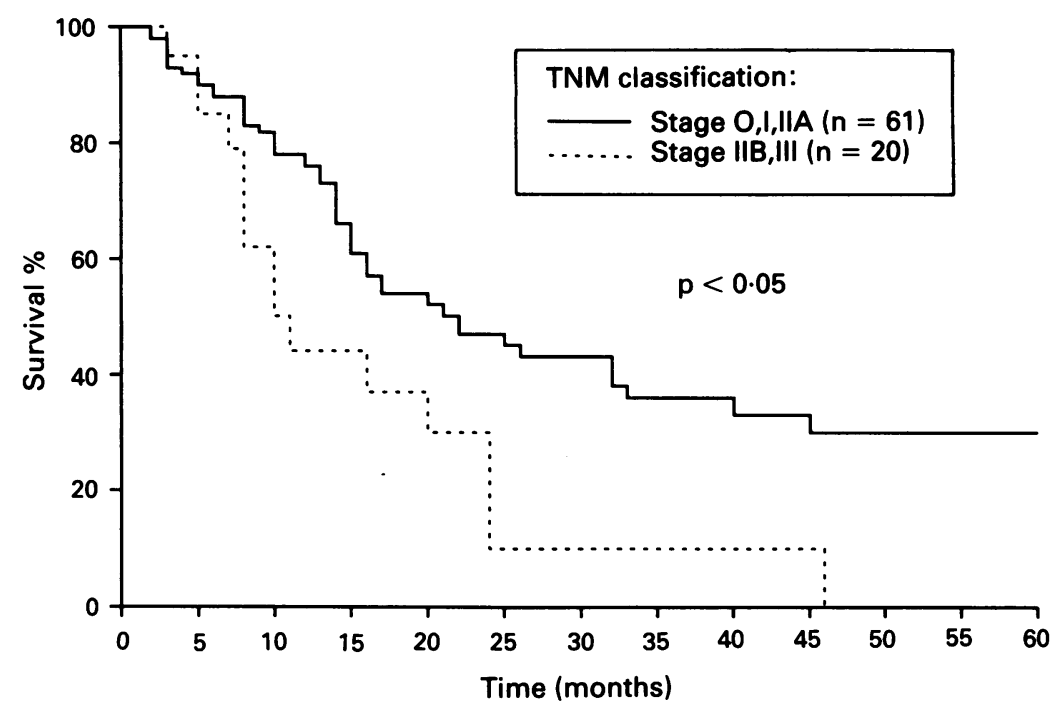

Figure 2: Survival of resected patients without regional lymph node metastases $(n=61)$ versus patients with regional lymph node metastases $(n=20)$.

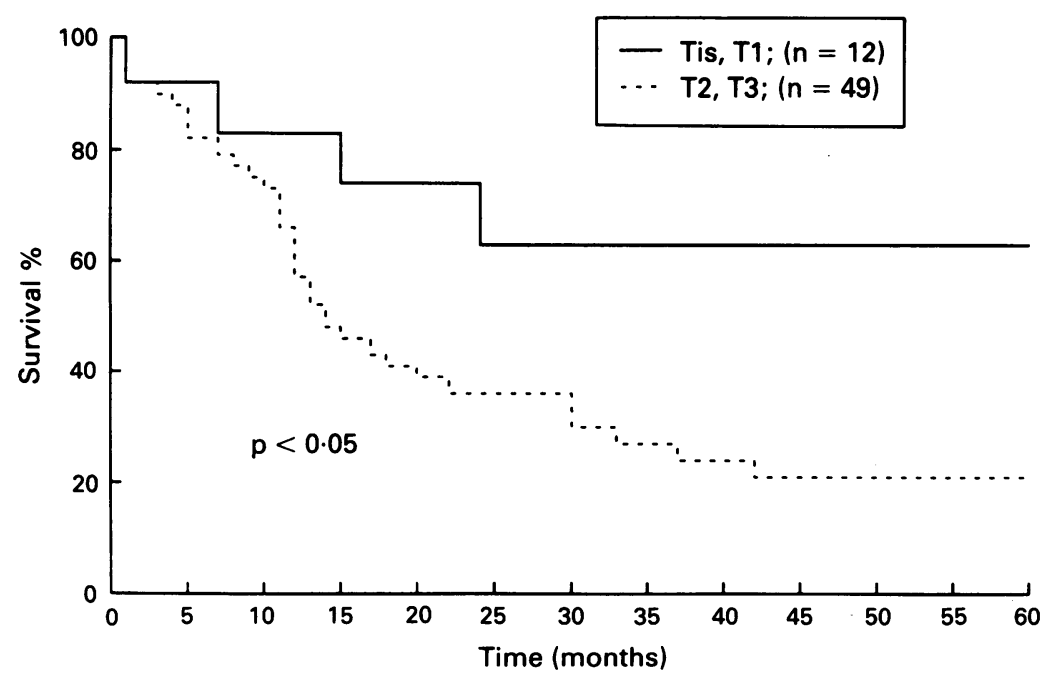

Figure 3: Survival of resected patients classified as stage 0 or $I(n=12)$ versus patients classified as stage IIA $(n=49)$.
6-107 months (mean 36 months) after resection of the tumour. Sixty two patients died from metastatic disease ( $72 \%$ of all deaths), 18 from causes unrelated to carcinoma, and in six cases the cause of death was unknown.

Life table analysis showed 1, 2, and 5 year survival rates of $57 \%, 31 \%$, and $17 \%$ respectively for the whole group. The 1,2 , and 5 year survival rates of the 85 patients who underwent oesophagectomy were $67 \%, 38 \%$, and $24 \%$ respectively, and for the 27 inoperable or unresectable patients the figures were $26 \%, 11 \%$, and $0 \%$ respectively ( $\mathrm{p}<0.001)$ (Fig 1$)$.

Within the group of resected patients $(n=85)$, there were no significant differences in survival between patients treated by preoperative radiation $(n=66)$ and those treated by resection alone $(n=19)$. Patients classified as stage $0, I$, or IIA (no regional lymph node metastases) had a significantly better survival $(\mathrm{p}=0.03$ ) with 1,2 , and 5 year survival rates of $76 \%, 47 \%$, and $30 \%$ respectively, compared with patients classified as stage IIB and III (regional lymph node metastases present), with 1,2 , and 5 year survival rates of $44 \%, 10 \%$, and $\leq 10 \%$ respectively (Fig 2). Patients with a Tis or T1 tumour without regional lymph node involvement $(n=12)$ had significantly better survival than patients with a $\mathrm{T} 2$ or T3 tumour without regional lymph node involvement $(n=49), p<0.05$ (Fig 3). Patients with well (GI) or moderately (GII) differentiated tumours classified as stage 0, I, IIA and IIB, III respectively did not show a significant better survival than patients with poorly differentiated (GIII) tumours (Fig 4).

\section{Discussion}

In 1950, Barrett described the condition of columnar epithelium lining a mediastinal stomach, secondary to a congenital short oesophagus. ${ }^{1}$ Allison and Johnstone suggested that columnar epithelium occurred in the lower oesophagus, secondary to gastro-oesophageal reflux. ${ }^{3}$ Since Barrett's description of the condition in the early $1950 \mathrm{~s},{ }^{2}$ many investigators have noted an association between columnar lined oesophagus and primary oesophageal carcinoma. ${ }^{+7}$

The reported mean age of patients with an adenocarcinoma associated with Barrett's oesophagus is about 57 years and the male to female ratio is $5 \cdot 5: 1 .^{13}$ In our series, the mean age was higher (63 years), and the male to female ratio was lower $(3 \cdot 1: 1)$ than reported, but still indi= cated a male predominance.

In our patient group, a major presenting symptom was dysphagia, which is in agreement with the presenting symptoms in the published reports.?

Controversy exists over the influence of medical or surgical treatment of gastrooesophageal reflux on Barrett's oesophagus. Medical treatment (antacids, $\mathrm{H}_{2}$ receptor blocking agents, prokinetic drugs) has no influence on the extent of Barrett's mucosa, ${ }^{13}$ but surgical correction of gastro-oesophageal reflux possibly leads to partial regression of Barrett's epithelium. ${ }^{14}$ is Fourteen patients in our series, however, had undergone antireflux surgery in the past. This suggests that an antireflux operation 


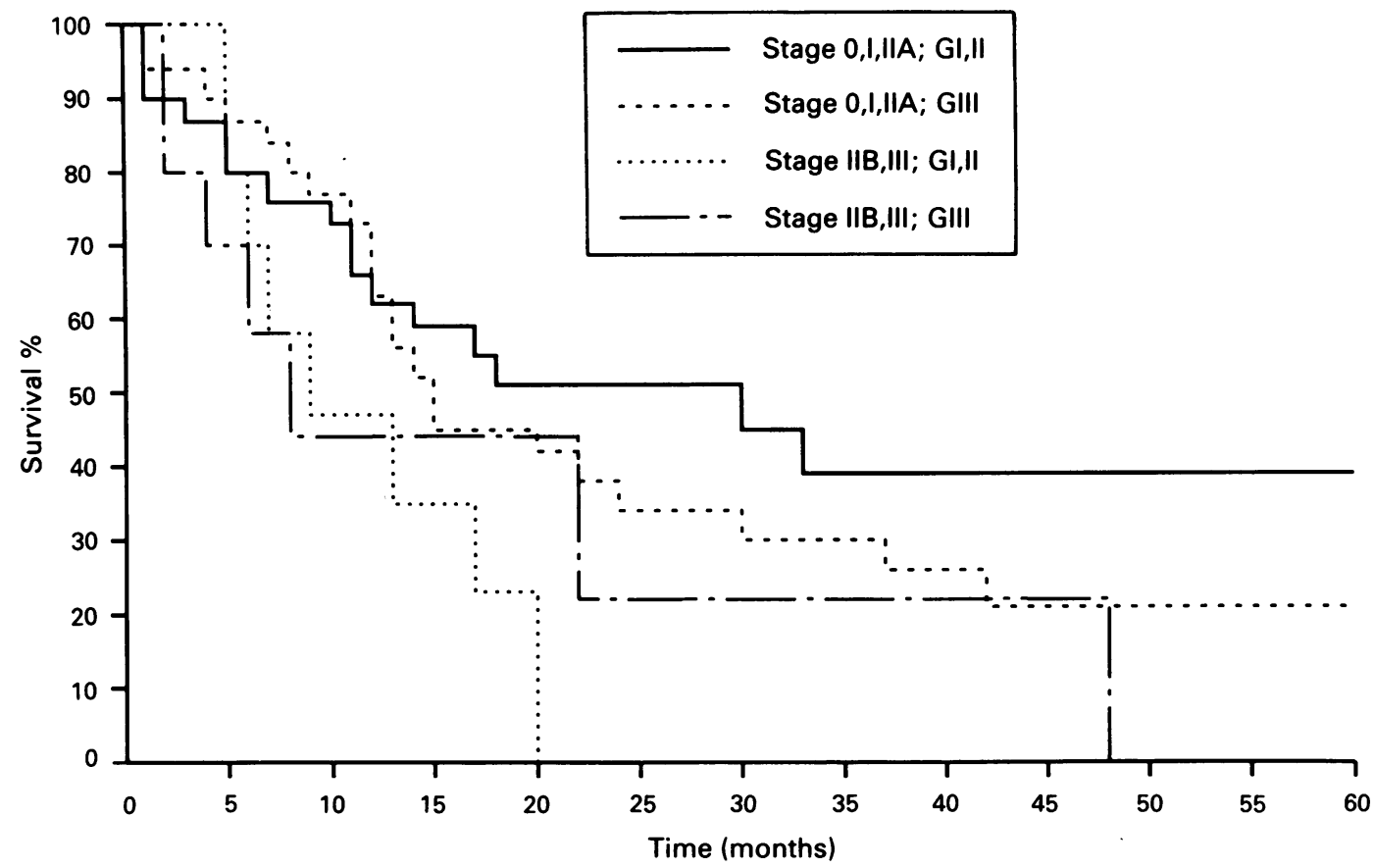

Figure 4: Survival of resected patients with well or moderately differentiated tumours $(G I, I I)$ versus patients with poorly differentiated tumours (GIII) staged respectively as stage $0, I, I I A$ and stage IIB, III.

will not inevitably lead to regression or resolution of Barrett's epithelium, and may not reduce the risk of malignant degeneration.

The treatment of choice most often reported for adenocarcinoma of the oesophagus is surgery. ${ }^{76} 17$ The reported postoperative mortality after oesophagectomy for carcinoma varies between 10 and $16 \% .^{7819}$ Most of these studies, however, comprised patient populations treated by varying surgical techniques, in the period before our study. While most patients with an adenocarcinoma associated with Barrett's oesophagus are resectable, the long term survival is low. In our series the 5 year overall survival was $17 \%$, and after resection and reconstruction it was $24 \%$, which agrees with the reported 5 year survival $(14 \cdot 5-22 \%) .^{717}$

Seventy two per cent of the resected patients did not have lymph node involvement, and more than one third (36\%) had neither node involvement nor full thickness penetration of the oesophageal wall, which has been reported as favourable. ${ }^{718}$

A clear correlation between the pathological staging of oesophageal tumours and prognosis has been reported - infiltration through the muscular wall and regional lymph node metastases, in particular, have a negative influence on survival rates. ${ }^{18} 2021$ Within the group of resected patients in our series, those without regional lymph node metastases showed significantly better survival than patients with regional lymph node metastases. Survival was significantly better in patients whose tumour was restricted to the submucosa and had not invaded the muscle layer.

The influence of the histological differentiation grade of adenocarcinomas in Barrett's oesophagus has not been reported before. For squamous cell carcinomas of the oesophagus, histological differentiation grade has no significant effect on survival. ${ }^{20}$ However, in one large series, including all types of oesophageal carcinomas, patients' late outcome was influenced significantly by tumour staging and histological grading. ${ }^{21}$ In our series the histological differentiation grade of the tumour had no significant influence on survival.

\section{Conclusion}

In most patients Barrett's oesophagus was not recognised before the diagnosis of an associated adenocarcinoma. If an adenocarcinoma in Barrett's oesophagus is diagnosed, resection offers the only chance for cure. In our series, 5 year survival after resection was $24 \%$. A correlation between pathological staging and survival was shown, with significantly better survival if the tumour was restricted to the submucosa and there were no regional lymph node metastases. Survival was not influenced by the histological differentiation grade of the tumour.

Presented at the autumn meeting of the British Society of Gastroenterology, 26-28 September 1990, University of Southampton.

1 Barrett NR. Chronic peptic ulcer of the oesophagus and oesophagitis. Brf Surg 1950; 38: 175-82.

2 Barrett NR. The lower oesophagus lined by columnar epithelium. Surgery 1957; 41: 881-94.

3 Allison PR, Johnstene AS. The oesophagus lined with gastric mucous membrane. Thorax 1953;8: 87-101.

4 Naef AP, Savary M, Ozzello L. Columnar-lined lower esophagus: an acquired lesion with malignant potential. F Thorac Vasc Surg 1975; 70: 826-35.

5 Hameeteman W, Tytgat GNJ, Houthoff HJ, Van den Twee JG. Barrett's esophagus: development of dysplasia and adenocarcinoma. Gastroenterology 1989; 96: 1249-56.

6 Starnes VA, Adkins RB, Ballinger JF, Sawyers JL. Barrett's esophagus. A surgical entity. Arch Surg 1984; 119: 563-7.

7 Sanfey H, Hamilton SR, Smith RRL, Cameron jL Carcinoma arising in Barrett's oesophagus. Surg Gynecol Obstet 1985; 161: 570-4.

8 Overhagen van $\mathrm{H}$, Lameris JS, Berger MY, et al. Supraclavicular lymph node metastases in carcinoma of the esophagus and gastro-esophageal junction: assessment with esophagus and gastro-esophageal junction: assessment with Radiology 1991; 79: $155-8$.

9 Launois B, Delarue D, Campion JP, Kerbaol M. Preoperative 
radiotherapy for carcinoma of the esophagus. Surg Gynecol Obstet 1981; 153: 690-2.

10 Gignoux M, Roussel A, Paillot B, et al. The value of preoperative radiotherapy in esophageal cancer: results of a study of the EORTC. World $\mathcal{F}$ Surg 1987; 11: 426-32.

11 UICC (International Union Against Cancer). TNM classification of malignant tumours. Berlin: Springer-Verlag, 1987.

12 Kaplan EL, Meier EA. Nonparametric estimation from incomplete observations. $\mathcal{F}$ Am Statist Assoc 1958; 53: 457 81 .

13 Sampliner RE, Garewal HS, Fennerty MB, Aickin M. Lack of impact of therapy on extant of Barrett's esophagus in 67 patients. Dig Dis Sci 1990; 35: 93-6.

14 Brand DL, Ylvisaker JT, Gelfand M, Pope CE. Regression of columnar esophageal (Barrett's) epithelium after antireflux surgery. N Engl f Med 1980; 302: 884-8.

15 Williamson WA, Ellis FH Jr, Gibb SP, Shahian DM, Aret: HT. Effect of antireflux operation on Barrett's mucosa. Ann Thorac Surg 1990; 49: 537-41.
16 Bremner CG. The management of columnar-lined oesophathe oesophagus. Edinburgh: Churchill Livingstone, 1988.

17 Skinner DB, Walther BC, Riddell RH, Schmidt H, Iascone C, DeMeester T. Barrett's esophagus: Comparison of benign and malignant cases. Ann Surg 1983; 198: 554-6.

18 Skinner DB, Ferguson MK, Soriano A, Little AG, Staszak $V M$. Selection of operation for oesophageal cancer based on VM. Selection of operation for oesoph.
staging. Ann Surg 1986; 204: 391-401.

19 Hennessy TPJ, O'Connell R. Surgical treatment of squamous cell carcinoma of the oesophagus. Br F Surg 1984; 71:750-1.

20 Hambraeus GM, Mercke CE, Willen R, Ranstam J Samuelsson L, Lamm IL. Prognostic factors influencing survival in combined radiotherapy and surgery of squamous cell carcinoma of the esophagus with special reference to histopathological grading system. Cancer 1988; 62: 895-904. 21 Muller JM, Jarczyk AJ, Huber P, Pichlmaier H. Ergebnisse der resektion der Speiserohre wegen einescarcinoms. Chirurg 1988; 59(69: 398-406. 